\title{
La investigación sobre la comunicación audiovisual en una facultad joven (Sevilla, 1989-2009).
}

Antonio Checa Godoy (Universidad de Sevilla )

http://dx.doi.org/10.12795/AdMIRA.2009.01.13

Resumen. En sus dos primeras décadas de existencia, la Facultad de Comunicación de la Universidad de Sevilla ha desarrollado una creciente y estimable actividad investigadora en el ámbito de la comunicación audiovisual, no exenta en todo caso de dificultades y rémoras. El presente trabajo analiza esas aportaciones al mundo de la imagen a través de la actividad de los grupos de investigación y revistas científicas surgidos en ella y del análisis de las tesis doctorales leídas en su seno, sin olvidar las aportaciones en libros, artículos de revistas y comunicaciones y ponencias, con sus rasgos y dependencias.

Palabras clave. Grupos de Investigación, Tesis, Imagen, Comunicación Audiovisual, Cine.

Al plantearnos un análisis y un balance de lo que ha supuesto las investigación en el ámbito de la comunicación audiovisual, la imagen, en el seno de una facultad que cumple 20 años, surge inevitable una primera pregunta, una duda: ¿cuál es, o debe ser, el tiempo de maduración de un centro universitario de las características y dimensiones -casi 3.000 alumnos, incluyendo posgrado- de la actual Facultad de Comunicación de la Universidad de Sevilla? Si en una empresa audiovisual, un nuevo canal de televisión, pongamos por caso, se asume que en su segunda temporada debe estar ya a pleno rendimiento y una imagen y público definidos, ¿cuándo se consolida una facultad que va a implantar su cuarto plan de estudios?

Podemos estimar en, al menos, un lustro o un sexenio, el tiempo mínimo para que una facultad de nueva creación se dote de unos primeros instrumentos y cauces para la investigación -constitución de departamentos específicos, formación de grupos de investigación, configuración de bibliotecas especializadas- y que esos instrumentos comiencen a dar sus frutos. $\mathrm{Y}$ un tiempo similar para que tales instrumentos, consolidados y perfeccionados, alcancen una primera madurez, es decir, ofrezcan ya frutos propios y relevantes.

En el caso de la actual Facultad de Comunicación de la Universidad de Sevilla, en principio Facultad de Ciencias de la Información, y el cambio no es baladí por cuanto supone una clara ampliación de horizontes, toda vez que comunicación es un concepto mucho más ambicioso que información, podemos decirse que ese calendario se cumple, 
aunque con muchas dificultades iniciales, unas dificultades con especial incidencia además en la investigación audiovisual, incluidas las agudas limitaciones técnicas de principio. Si la Facultad comienza a impartir clases en el curso 1989-1990, solo en 1991 asomará el primer departamento con sede en ella, de suma complejidad en sus inicios, como evidencia la propia denominación -Departamento de Comunicación Audiovisual y Publicidad, Periodismo, Literatura y Estética-, que tras dos segregaciones (Estética en 1994 y Periodismo en 1998) quedará desde ese 1998 en Departamento de Comunicación Audiovisual y Publicidad y Literatura, cauce principal de la investigación en imagen, y que, por volumen del alumnado, profesorado con que cuenta, asignaturas que imparte y número de tesis leídas, entre otros parámetros, viene figurando en los últimos cursos entre los cinco primeros de la Universidad de Sevilla.

A finales del primer lustro, en 1993, se inicia la lectura de tesis doctorales elaboradas en el seno de la Facultad, nuevo departamento, y a partir de 1995 se van configurando los grupos de investigación sobre comunicación audiovisual en su seno. De inmediato llama la atención el alto número de tesis leídas en ese joven y amplio departamento: 4 en 1993, 7 en 1995, 6 en 1996, 7 en 1997...; que no disminuye en los años siguientes pese a las segregaciones, pero también, desde una visión ya estrictamente orientada a la comunicación audiovisual, la constitución de tres grupos de investigación sobre imagen: Historia del cine español y sus relaciones con otras artes, que dirige el profesor Utrera Macías, grupo que recibe las primeras ayudas en 1997; Historia de la imagen en movimiento y música audiovisiva, que dirige el profesor Carlos Colón Perales y obtiene asimismo las primeras subvenciones en 1997, e Historia, lenguaje y tecnología audiovisuales, dirigido por el profesor Francisco Perales Bazo, cuyas primeras ayudas datan del año 2000. La propia configuración del departamento, por demás, implica que la investigación audiovisual no se limita a la encauzada por esos grupos, toda vez que los tres constituidos en el área de Literatura del mismo abordan igualmente cuestiones vinculadas con el mundo de la imagen, como traslucen sus propias denominaciones: Teoría y tecnología de la Comunicación, dirigido por el profesor Manuel Ángel Vázquez Medel; Literatura, transtextualidad y nuevas tecnologías, grupo dirigido por la profesora María Elena Barroso Villar, y Literatura Española y Comunicación, dirigido por la profesora Pilar Bellido Navarro, y sin olvidar que desde el ámbito de la Publicidad y las RR PP, el grupo constituido en su seno, Métodos, análisis y estrategias de la comunicación empresarial e institucional, dirigido 
por el profesor Juan Rey Fuentes, aborda igualmente aspectos que unen la publicidad y la comunicación audiovisual, desde el spot televisivo al videoclips.

A ese panorama se une la aparición en 2002 de la revista Comunicación, impulsada por el Departamento, como revista anual de comunicación audiovisual y publicidad y estudios culturales, de amplio contenido, que en 2009, en aras de una mayor difusión de sus contenidos, pasa a edición electrónica.

\section{Grupos de investigación}

En el segundo lustro de los años noventa se configuran tres grupos de investigación en el seno de la Facultad de Comunicación, orientados al estudio de la comunicación audiovisual. A ellos se unirá recientemente, ya en 2008, un cuarto grupo.

El que impulsa el profesor Carlos Colón Perales, Historia de la imagen en movimiento y música audiovisiva, de siglas Himma, (HUM406), declara como líneas de investigación el "Estudio de las relaciones entre la música y la imagen. Nuevos planteamientos historiográficos de la historia del cine. Cultura popular y cine. Evolución de matrices narrativas y figurativas. Cine e historia de la vida cotidiana y de las mentalidades". En la práctica se orienta sobre todo a la investigación de la historia del cine y de la música cinematográfica. Reúne a ocho investigadores, de ellos tres son profesores estables de la Facultad. El grupo mantiene actividad hasta aproximadamente 2004, pero decae luego. No ha obtenido ayudas desde 2000.

El profesor Rafael Utrera Macías crea en 1995 el grupo Historia del cine español y sus relaciones con otras artes, siglas Eihceroa, (HUM443). El grupo se orienta "tanto al desarrollo de actividades investigadoras en el ámbito de la evolución histórica del cine español como a las múltiples relaciones con cuantas artes y oficios intervienen en el proceso creador del film y de otros medios audiovisuales". En la práctica, se dirige sobre todo a investigar sobre cine. Integra a un promedio de ocho investigadores, en su gran mayoría profesores de la Facultad de Comunicación sevillana. Viene obteniendo ayudas desde 1997 y ha mantenido una actividad estable, fruto de la cual ha sido la edición de media docena de publicaciones colectivas en el periodo 1997-2009, mas una decena de publicaciones individuales propiciadas por el grupo-Cuadernos de Eihceroa-, prácticamente todas relacionadas con el cine.

El profesor Francisco Perales Bazo es el impulsor de otro grupo, Historia, lenguaje y tecnología audiovisuales (HUM656), cuyas líneas de investigación básicas 
son: "Andalucía como escenario filmico. Industria, plató, recreación y evocación. Presencia de Andalucía en la cinematografía española y extranjera. Evolución, historia e interpretación entre tecnología y lenguaje audiovisual". El grupo se constituye con una decena de investigadores, con clara mayoría de profesores de la Facultad. Mantiene actividad estable, viene obteniendo ayudas a la investigación desde 2000 y ha publicados varias obras colectivas, centradas sobre todo en el mundo del cine.

Ese panorama, bastante estable, y claramente enseñoreado por el cine, se enriquece en 2008 con la aparición de un nuevo grupo de investigación en comunicación audiovisual, dirigido por la profesora Virginia Guarinos, Análisis de medios, imágenes y relatos audiovisuales en su historia para el cambio social, siglas Admira. Como líneas de investigación: "Narrativa audiovisual: fílmica, televisiva, radiofónica, gráfica y multimedia. Historia de los medios audiovisuales. Alfabetización audiovisual. Estudios culturales. Estudios de género". El grupo integra a una decena de investigadores, varios de ellos -todos profesores-, procedentes de otros grupos de investigación del centro a los que se unen varios jóvenes investigadores provenientes del alumnado de la propia facultad. Obtiene en 2008 sus primeras ayudas y se orienta al mundo de la comunicación audiovisual con mucha más diversidad y audacia y menor querencia por el cine.

Al concluir el curso 2008-2009 los cuatro grupos aglutinan a 32 investigadores, de los que 18 son profesores de la facultad, todos integrados en el Departamento de Comunicación Audiovisual y Publicidad y Literatura.

\section{Cuadro $n^{0} 1$}

Obras colectivas publicadas o coordinadas por los grupos de investigación en Comunicación Audiovisual de la Facultad de Comunicación.

\begin{tabular}{|l|l|r|}
\hline Obra & Grupo & Año \\
\hline Imágenes cinematográficas de Sevilla. & $\begin{array}{l}\text { Historia del cine español y } \\
\text { sus relaciones con otras } \\
\text { artes }\end{array}$ & 1997 \\
\hline $\begin{array}{l}\text { Cien años de cine: la fábrica y los } \\
\text { sueños (coordinación) }\end{array}$ & $\begin{array}{l}\text { Historia de la imagen en } \\
\text { movimiento y música } \\
\text { audiovisiva }\end{array}$ & 1999 \\
\hline $\begin{array}{l}8 \text { calas cinematográficas en la literatura } \\
\text { de la Generación del 98. }\end{array}$ & $\begin{array}{l}\text { Historia del cine español y } \\
\text { sus relaciones con otras } \\
\text { artes }\end{array}$ & $\begin{array}{l}\text { Historia, lenguaje y } \\
\text { tecnología audiovisuales }\end{array}$ \\
\hline $\begin{array}{l}\text { Andalucía, una civilización para el } \\
\text { cine. }\end{array}$ & & \\
\hline
\end{tabular}




\begin{tabular}{|l|l|r|}
\hline $\begin{array}{l}\text { Cine, arte y artilugios en el panorama } \\
\text { español. }\end{array}$ & $\begin{array}{l}\text { Historia del cine español y } \\
\text { sus relaciones con otras } \\
\text { artes }\end{array}$ & 2002 \\
\hline El sueño audiovisual & $\begin{array}{l}\text { Historia de la imagen en } \\
\text { movimiento y música } \\
\text { audiovisiva }\end{array}$ & 2004 \\
\hline $\begin{array}{l}\text { Katharine Hepburn: figura y genio de } \\
\text { actriz }\end{array}$ & $\begin{array}{l}\text { Historia del cine español y } \\
\text { sus relaciones con otras } \\
\text { artes }\end{array}$ & 2005 \\
\hline $\begin{array}{l}\text { Andalucía, un siglo de fascinación. } \\
\text { Homenaje a Basilio Martín Patino }\end{array}$ & $\begin{array}{l}\text { Historia del cine español y } \\
\text { sus relaciones con otras } \\
\text { artes }\end{array}$ & 2006 \\
\hline Cine y publicidad & $\begin{array}{l}\text { Historia, lenguaje y } \\
\text { tecnología audiovisuales }\end{array}$ & 2007 \\
\hline $\begin{array}{l}\text { Duetos de Cine. Coproducciones } \\
\text { hispanocubanas con música de fondo }\end{array}$ & $\begin{array}{l}\text { Historia del cine español y } \\
\text { sus relaciones con otras } \\
\text { artes }\end{array}$ & $\begin{array}{l}\text { Historia, lenguaje y } \\
\text { tecnología audiovisuales }\end{array}$ \\
\hline $\begin{array}{l}\text { Marlon Brando: un rebelde en } \\
\text { Hollywood }\end{array}$ & & 2009 \\
\hline
\end{tabular}

Fuente: elaboración propia

\section{Tesis doctorales.}

Desde 1993, primera tesis defendida en la facultad, a la conclusión del curso 2008-2009 se han leído en el Departamento de Comunicación Audiovisual y Publicidad y Literatura, incluida la etapa predecesora de 1993-1998, 34 tesis doctorales claramente vinculadas con la comunicación audiovisual, sobre un total de $84(40 \%)$ defendidas en el Departamento en torno a alguno de sus tres ámbitos actuales de conocimiento Comunicación Audiovisual, Publicidad y Literatura-, es un número estimable, pues descontando el interregno de formación (1989-2002), supone algo más de 2 tesis por año. Pero si se analiza la trayectoria, lo que llama la atención sobre todo es el proceso de crecimiento inmediato y la estabilización posterior, pues si entre 1995 (primera tesis que se lee sobre imagen) y 1999, un lustro, se defienden 9 tesis, en los dos lustros siguientes, 2000-2004 y 2005-2009 (éste hasta mayo), son 15 y 10 respectivamente.

Un dato significativo: si en el primer lustro resalta que la casi totalidad de los nuevos doctores se orientan a la docencia en la propia facultad (8 de 9), y la tesis es paso obligado en su carrera docente, esa dedicación desciende posteriormente, conforme se estabiliza el profesorado de la facultad, de forma que entre 2000 y 2009 sólo 10 de los 25 nuevos doctores ejercen como docentes. 
Además, en los departamentos de Periodismo se han leído desde 1998 segregación- una docena de tesis sobre comunicación audiovisual, orientadas sobre todo a análisis de la estructura de los medios y de los contenidos televisivos.

No obstante, ese número, estimable, de tesis defendidas, no debe hacernos olvidar algunos aspectos no tan positivos e incluso alguno preocupante. Llama de inmediato la atención el elevado porcentaje que representan las tesis sobre cine, once, justo un tercio; incluso si se añaden las que tratan aspectos inmediatos -música de cine por ejemplo- el número se incrementa y se acerca al 50\%. Por otro lado, sectores relevantes aparecen prácticamente ausentes -como el vídeo o la música discográfica- o poco representados, como el cómic, la fotografía, la radio o la propia televisión, en otros ámbitos tan omnipresente.

Esa sobrerrepresentación del cine entre las tesis doctorales tiene sus razones, una de ellas la propia orientación de los grupos de investigación, a la que ya hemos aludido, pero también influyen la amplia representación del cine en los planes de estudios, la propia imagen del cine como alta cultura audiovisual frente a una baja cultura audiovisual en la que se ubicaría la televisión, en el ámbito de la historia incidiría la amplia trayectoria -y reconocimiento académico- de la historia del cine, un siglo, en contraste con la mucho más corta de otros medios audiovisuales, en especial la televisión. Por otro lado, el área de Literatura del Departamento viene aportando numerosos trabajos sobre literatura y cine, pero son mucho más escasos los que se centran en otras relaciones con el mundo audiovisual.

Anotemos, sin embargo, por significativa contraposición, la defensa de varias tesis sobre la televisión en el seno de los dos departamentos de Periodismo de la Facultad, sobre todo Periodismo II: Los inicios de la televisión por cable en España, 1999; El programa 'Tierra y Mar' de Canal Sur TV, 1999; El uso de la documentación audiovisual en los programas informativos diarios, 1999; La televisión pública europea en el contexto del estado del bienestar y de las políticas audiovisuales, 2005; El periodismo emotivo: una aproximación al mensaje en el medio televisivo, 2005; Métodos de producción en la retransmisión televisiva en directo de partidos de fútbol, 2006.

En el ámbito de las memorias de investigación se reproducen los mismos problemas, con escasas variantes. Hasta el final del curso 2008-2009 se habían leído en el seno del Departamento de Comunicación Audiovisual y Publicidad y Literatura, 120 
memorias o tesinas, de los que casi medio centenar eran de cuestiones vinculadas con la comunicación audiovisual, pero entre ellas el cine mantiene su hegemonía, más de la mitad, y muchos otros sectores del variopinto mundo audiovisual muestran una mínima representación.

Cuadro $n^{\circ} 2$

Tesis doctorales sobre comunicación audiovisual leídas en el Departamento de Comunicación Audiovisual y Publicidad y Literatura de la Universidad de Sevilla (1993-2009).

\begin{tabular}{|c|c|c|}
\hline Tesis & Autor & $\begin{array}{l}\text { Año de } \\
\text { lectura }\end{array}$ \\
\hline $\begin{array}{l}\text { Aproximación al universo fílmico de } \\
\text { Luis García Berlanga }\end{array}$ & Francisco Perales Bazo & 1995 \\
\hline $\begin{array}{l}\text { Influencia del montaje en el lenguaje } \\
\text { audiovisual }\end{array}$ & $\begin{array}{l}\text { Manuel Carlos Fernández } \\
\text { Sánchez }\end{array}$ & 1995 \\
\hline $\begin{array}{l}\text { Teoría e Historia de la representación } \\
\text { fotográfica: de lo real y lo imaginario en } \\
\text { la comunicación fotopublicitaria }\end{array}$ & Diego Coronado Hijón & 1996 \\
\hline $\begin{array}{l}\text { El informativo diario de televisión como } \\
\text { discurso narrativo }\end{array}$ & Inmaculada Gordillo Álvarez & 1997 \\
\hline $\begin{array}{l}\text { La aportación infográfica al medio } \\
\text { audiovisual }\end{array}$ & $\begin{array}{l}\text { Fernando R. Contreras } \\
\text { Medina }\end{array}$ & 1997 \\
\hline $\begin{array}{l}\text { La imagen del indígena americano en la } \\
\text { Europa del siglo XVI: determinantes de } \\
\text { la representación icónica }\end{array}$ & $\begin{array}{l}\text { María del Mar Ramírez } \\
\text { Alvarado }\end{array}$ & 1997 \\
\hline $\begin{array}{l}\text { Principales transformaciones del mercado } \\
\text { audiovisual español en el periodo 1989- } \\
\text { 1996: el fin del monopolio y la aparición } \\
\text { de nuevas ofertas audiovisuales }\end{array}$ & $\begin{array}{l}\text { Diego Antonio Velázquez } \\
\text { Mallofret }\end{array}$ & 1998 \\
\hline El teatro radiofónico & Dra.Virginia Guarinos & 1998 \\
\hline Historia de la radio en Andalucía & Antonio Checa Godoy & 1999 \\
\hline $\begin{array}{l}\text { La industria audiovisual en Andalucía en } \\
\text { la década de los noventa }\end{array}$ & $\begin{array}{l}\text { Eva María González } \\
\text { Hernández }\end{array}$ & 2000 \\
\hline $\begin{array}{l}\text { Ana Mariscal (1921-1995). } \\
\text { Biofilmografía de una cineasta española }\end{array}$ & Victoria Fonseca Aguilar & 2000 \\
\hline $\begin{array}{l}\text { Introducción del cinematógrafo en los } \\
\text { usos del ocio sevillano }\end{array}$ & Begoña Soto Vázquez & 2001 \\
\hline $\begin{array}{l}\text { Aproximación histórica a la figura y la } \\
\text { obra del cineasta Francisco Elías } \\
\text { Riquelme (1890-1977) }\end{array}$ & Enrique Sánchez Oliveira & 2001 \\
\hline $\begin{array}{l}\text { Narrativa de la historieta.Análisis } \\
\text { narratológico del cómic a través de la } \\
\text { obra de Alan Moore }\end{array}$ & Jesús Jiménez Varea & 2002 \\
\hline $\begin{array}{l}\text { La imagen de Andalucía en el cine } \\
\text { español (1940-1960) }\end{array}$ & Antonio Periañez Orihuela & 2002 \\
\hline
\end{tabular}




\begin{tabular}{|c|c|c|}
\hline $\begin{array}{l}\text { Técnica y tecnología del sonido } \\
\text { cinematográfico }\end{array}$ & Juan José Domínguez López & 2003 \\
\hline $\begin{array}{l}\text { Aplicación del lenguaje atonal a la } \\
\text { música cinematográfica }\end{array}$ & María de Arcos Rus & 2003 \\
\hline $\begin{array}{l}\text { Comunicación pública de la ciencia: } \\
\text { Recursos de divulgación en Internet de } \\
\text { las universidades españolas }\end{array}$ & Antonio Rial García & 2003 \\
\hline $\begin{array}{l}\text { El primitivo cinematógrafo de Sevilla } \\
\text { (1896-1906) a través de programas de } \\
\text { mano y prensa local }\end{array}$ & Mónica Barrientos Bueno & 2003 \\
\hline $\begin{array}{l}\text { Historia de un género cinematográfico. } \\
\text { La españolada }\end{array}$ & Luis Navarrete Cardero & 2004 \\
\hline Espacio sonoro y construcción social & Jesús Ángel Baca Martín & 2004 \\
\hline $\begin{array}{l}\text { El diseño del sonido en el cine. Un } \\
\text { emplazamiento sonoro. }\end{array}$ & $\begin{array}{l}\text { Francisco José Cuadrado } \\
\text { Méndez }\end{array}$ & 2004 \\
\hline $\begin{array}{l}\text { La definición del protagonista en el cine } \\
\text { de Hollywood (1930-1960) }\end{array}$ & José Patricio Pérez Rufi & 2004 \\
\hline $\begin{array}{l}\text { La música clásica en el cine: Stanley } \\
\text { Kubrick }\end{array}$ & Rafael Prado Pérez & 2004 \\
\hline $\begin{array}{l}\text { El espejo deformado: procesos de } \\
\text { intertextualidad en la ficción audiovisual } \\
\text { norteamericana }\end{array}$ & $\begin{array}{l}\text { Concepción Carmen } \\
\text { Cascajosa Virino }\end{array}$ & 2005 \\
\hline $\begin{array}{l}\text { Relato literario y relato cinematográfico, } \\
\text { cauces para un espacio mítico. Laberinto } \\
\text { y caos en El tercer hombre }\end{array}$ & $\begin{array}{l}\text { María Ángeles Martínez } \\
\text { García }\end{array}$ & 2005 \\
\hline $\begin{array}{l}\text { La conciencia trágica en la poética } \\
\text { cinematográfica de Pier Paolo Pasolini }\end{array}$ & Javier Fernández Zulueta & 2005 \\
\hline La realización del deporte en televisión & Joaquín Marín Montín & 2006 \\
\hline $\begin{array}{l}\text { Pequeños directores: el documento } \\
\text { audiovisual creado por niños }\end{array}$ & $\begin{array}{l}\text { Carmen Jacqueline Sánchez } \\
\text { Carrero }\end{array}$ & 2006 \\
\hline $\begin{array}{l}\text { Transformaciones de la realidad social a } \\
\text { través de los procesos de comunicación } \\
\text { en Red. La búsqueda en Google como } \\
\text { ejemplo paradigmático. }\end{array}$ & Antonio Gómez Aguilar & 2008 \\
\hline $\begin{array}{l}\text { Carlos Saura. Cine musical flamenco y } \\
\text { estética de lo trágico }\end{array}$ & Pedro Javier Millán Barroso & 2008 \\
\hline $\begin{array}{l}\text { Impacto de las nuevas tecnologías en la } \\
\text { composición de bandas sonoras }\end{array}$ & $\begin{array}{l}\text { Francisco Javier Torres } \\
\text { Simón }\end{array}$ & 2008 \\
\hline $\begin{array}{l}\text { Estructura y análisis de la programación } \\
\text { de TVE (1958-1962): los años pioneros }\end{array}$ & $\begin{array}{l}\text { Natividad Cristina Carreras } \\
\text { Lario }\end{array}$ & 2008 \\
\hline $\begin{array}{l}\text { Los sueños de Akira Kurosawa: Espacios } \\
\text { simbólicos. }\end{array}$ & Candelaria Vizcaíno Macero & 2009 \\
\hline
\end{tabular}

Fuente. Elaboración propia

Cuadro $n^{\circ} 3$

Distribución por contenidos de las tesis doctorales sobre Comunicación Audiovisual leídas en la Facultad de Comunicación de Sevilla 


\begin{tabular}{|l|l|r|r|}
\hline Contenidos & $\begin{array}{l}\text { Departamento de } \\
\text { Comunicación } \\
\text { Audiovisual y } \\
\text { Publicidady } \\
\text { Literatura }\end{array}$ & Otros & Total \\
\hline Cine & 11 & - & 11 \\
\hline Cómic & 1 & - & 1 \\
\hline $\begin{array}{l}\text { Empresa audiovisual y } \\
\text { estructura de los medios }\end{array}$ & 2 & 2 & 4 \\
\hline Fotografía & 1 & 1 & 2 \\
\hline Internet & 2 & 2 & 4 \\
\hline Lenguaje audiovisual & 1 & & 1 \\
\hline Radio & 2 & - & 2 \\
\hline Sonido (y música) & 5 & & 2 \\
\hline Tecnología audiovisual & 2 & - & 9 \\
\hline Televisión & 4 & 5 & 1 \\
\hline Vídeo & 1 & - & 3 \\
\hline Otros & 2 & 1 & 45 \\
\hline Total & & & \\
\hline Fuente: elaboracion propar & & & \\
\hline
\end{tabular}

Fuente: elaboración propia.

\section{Publicaciones}

Al margen de la actividad generada en el seno de los grupos de investigación en comunicación audiovisual, en las dos décadas de existencia de la Facultad de Comunicación de la Universidad de Sevilla, las publicaciones del profesorado de la misma han sido en esa etapa muy numerosas, en coincidencia con la expansión bibliográfica sobre comunicación audiovisual en toda España.

Un acercamiento a esta producción bibliográfica, utilizando las principales fuentes disponibles, confirma también en el terreno de las monografías las tendencias aludidas, el número de libros publicados sobre cine supera el 50\% de los publicados y es escaso el de obras dedicadas al cómic, la fotografía o el vídeo y comparativamente bajos los dedicados a radio y televisión, y compone un grupo estimable el dedicado a análisis de los medios audiovisuales en general y de la industria audiovisual. Es probable que en esos datos influyan las mayores posibilidades de publicar sobre cine, por la abundancia de editoriales, festivales y eventos a él dedicados.

El número de monografías procede de una veintena de investigaciones, en tanto un tercio del profesorado de Comunicación Audiovisual no ha publicado obras en solitario. 
Por el contrario, las publicaciones, comunicaciones y ponencias, procedentes de congresos y aparecidas en obras colectivas, muestran mucha más diversidad y menor presencia del cine, y probablemente anuncian un paulatino cambio de tendencia. En la última década, y sobre todo en el último lustro, el número de artículos en revistas científicas -incluidas las extranjeras- ha crecido notablemente, en razón también de su mayor valoración por instituciones oficiales de acreditación académica, se constata que la presencia en congresos nacionales e internacionales prácticamente se triplica en el quinquenio 2004-.2008 sobre la alcanzada en el periodo 1996-2000. menudean en las últimas fechas las publicaciones en revistas internacionales -aunque todavía en porcentaje muy inferior al deseable-, artículos prácticamente inexistentes en la última década del pasado siglo.

Cuadro $n^{\circ} 4$

Monografías sobre comunicación audiovisual publicadas por el profesorado de la Facultad de Comunicación de la Universidad de Sevilla (1989-2009).

\begin{tabular}{|l|r|}
\hline Tema & Publicaciones estimadas \\
\hline Cine (incluye música cinematográfica) & 40 \\
\hline Comic & 2 \\
\hline Fotografia & 3 \\
\hline Internet & 5 \\
\hline Medios audiovisuales en general y empresa audiovisual & 10 \\
\hline Radio & 6 \\
\hline Televisión & 6 \\
\hline Vídeo & 1 \\
\hline Otros & 3 \\
\hline Total & 76 \\
\hline
\end{tabular}

Fuente: elaboración propia sobre datos de Sisius (Universidad de Sevilla), Dialnet (Universidad de La Rioja) y Biblioteca Nacional (Catálogo en red). Solo se consideran obras únicas. No se incluyen folletos (menos de 80 páginas).

\section{Conclusiones}

Puede concluirse del análisis de los datos ofrecidos, que la investigación sobre comunicación audiovisual en el seno de la Facultad de Comunicación, y muy especialmente en el Departamento de Comunicación Audiovisual y Publicidad y Literatura, ha alcanzado un volumen y un nivel estimables, pero dista mucho aún de llegar a los niveles deseables y debiera diversificarse en los próximos años, atendiendo mucho más, sobre todo, a internet y nuevas tecnologías, pero también televisión o 
fotografia. Un sector importante tanto del Departamento como de la Facultad en general, presenta un nivel muy bajo de investigaciones, y en consecuencia, de publicaciones, en especial el sector de profesores asociados que aúnan la actividad profesional y la docencia. Pero el camino recorrido en las dos décadas de existencia de la Facultad es largo, la trayectoria positiva, en especial en los años iniciales del siglo XXI, y cabe esperar razonablemente su continuidad y mejora.

\section{Fuentes}

\section{Bibliográficas}

REIG, Ramón, y GARCIA ORTA, María José (2000), “Investigación sobre comunicación en Sevilla. Once años de la Facultad de Ciencias de la Información, 1989-2000", en Ámbitos, no 5, Sevilla, pp. 259-311.

SIERRA CABALLERO, Francisco, y RAMIREZ ALVARADO, María del Mar (2007), Catálogo de grupos de investigación, 2006-2007, Facultad de Comunicación, Sevilla, $122 \mathrm{pp}$

\section{Electrónicas}

www.bne.es

http://dialnet.unirioja.es

http://investigacion.us.es/sisius 